\title{
Nodulose pelo Uso de Metotrexato em Doente com Artrite Reumatoide
}

\author{
Francisco Ronaldo Moura Filho', Aline Guimarães Grana', Aline do Amaral Silva', Suzi Marla Carvalho Maron ', Bárbara Rodovalho5, \\ Fabio Francesconi ${ }^{6}$ \\ 'Médico Residente/Resident, Dermatology, Serviço de Dermatologia do Hospital Universitário Getúlio Vargas (HUGV), Universidade \\ Federal do Amazonas (UFAM), Manaus (AM), Brazil \\ ${ }^{2}$ Acadêmica de Medicina/Academic Medicine, Universidade Federal do Amazonas, Manaus (AM), Brazil \\ ${ }^{3}$ Dermatologista Especialista pela Sociedade Brasileira de Dermatologia/Specialist in Dermatology, Mestre em Medicina Tropical/ \\ Master in Tropical Medicine, Universidade do Estado do Amazonas, Manaus (AM)
}

RESUMO - As manifestações extra-articulares em pacientes com artrite reumatóide são comuns. Os nódulos subcutâneos aparecem em cerca de $8 \%$ dos usuários de metotrexato com artrite reumatoide. O metotrexato, uma das drogas de escolha nesta doença, pode acarretar o aparecimento de efeitos indesejados como a nodulose acelerada. Esta complicação é um importante diagnóstico diferencial de nódulos subcutâneos com evolução rápida em pacientes com artrite reumatoide e uso de metotrexato e inibidores de TNF. O diagnóstico precoce é fundamental para que seja instalado tratamento efetivo. Descreve-se um caso de nodulose acelerada associado ao uso de MTX e etanercept em paciente com artrite reumatoide.

PALAVRAS-CHAVE - Artrite Reumatoide; Metotrexato/efeitos adversos; Nódulos Reumatóides; Tecido Subcutâneo.

\section{Nodulosis by the use of the Methotrexate in Patient with Rheumatoid Arthritis}

ABSTRACT - Extra-articular manifestations in patients with rheumatoid arthritis are common. Subcutaneous nodules appear in almost $8 \%$ of users of methotrexate with rheumatoid arthritis. Methotrexate, one of the recommended drugs in this disease, may cause unwanted effects such as accelerated nodulosis. This complication is an important differential diagnosis in subcutaneous nodules rapidly evolving in rheumatoid arthritis patients on methotrexate and TNF inhibitors. Early diagnosis is essential for a forehand treatment. We describe a case of accelerated nodulosis associated with the use methotrexate and etanercept in patients with rheumatoid arthritis. KEY-WORDS - Arthritis, Rheumatoid; Methotrexate/adverse effects; Rheumatoid Nodule; Subcutaneous Tissue

\section{INTRODUÇÃO}

A artrite reumatoide $(A R)$ é uma doença inflamatória e autoimune que tem como principal manifestação clínica o acometimento de pequenas articulações. As manifestações extra-articulares são comuns, envolvendo a pele, coração, pulmões e olhos, sendo a presença de nódulos subcutâneos e vasculites os achados mais comuns. ${ }^{1,2}$

O metotrexato (MTX) é um fármaco com propriedades imunomoduladoras indicado principalmente no tratamento de doenças não oncológicas, tais como AR do adulto, artrite idiopática juvenil, polimiosite, dermatomiosite, artrite psoriática e psoríase cutânea. ${ }^{1}$ Reações adversas importantes são relatadas, quando associado ou não a outros fármacos, ${ }^{3}$ sendo já bem estabelecida na literatura clínica o surgimento de nódulos subcutâneos no tratamento da AR com MTX.1,2,4 A nodulose acelerada (NA) é caracterizada pelo aparecimento de uma grande quantidade de nódulos reumatóides em um breve intervalo de tempo. ${ }^{5}$

Trabalho realizado no Ambulatório Araújo Lima do Hospital Universitário Getúlio Vargas (HUGV), Universidade Federal do Amazonas (UFAM), Brazil.

Correspondência: Francisco Ronaldo Moura Filho

Rua Ramos Ferreira,199, Aparecida - CEP: 69010120, Manaus, AM, Brazil

Tel.: +55 85997366000 - Tel.: +5592981076000

E-mail: fronaldomoura@hotmail.com
Recebido/Received

12 Julho/12 July 2016

Aceite/Accepted

6 Outubro/6 October 2016 


\section{Caso Clínico}

O objetivo deste trabalho é relatar um paciente com AR que apresentou nódulos reumatoides após o início do uso do MTX. Este relato destaca a importância de considerar NA como diagnóstico diferencial em pacientes com AR em tratamento com MTX e inibidores de TNF.

\section{CASO CLÍNICO}

Doente do sexo feminino, 39 anos de idade, referenciada a um Serviço de Dermatologia da cidade de Manaus, capital do Estado do Amazonas, Brasil em setembro de 2015 por apresentar nódulos subcutâneos que surgiram em mãos e pés. Relatou que em 2012 foi diagnosticada com AR fator reumatóide positivo sendo iniciado tratamento com MTX $(15 \mathrm{mg}$ por semana), associado à prednisona (10mg por dia) e ácido fólico (5mg por semana). Em maio de 2014 foi associado etanercept (50mg por semana) pela Reumatologia por agravamento do quadro clínico de AR. Quando questionada acerca dos nódulos subcutâneos, a paciente referia o seu surgimento

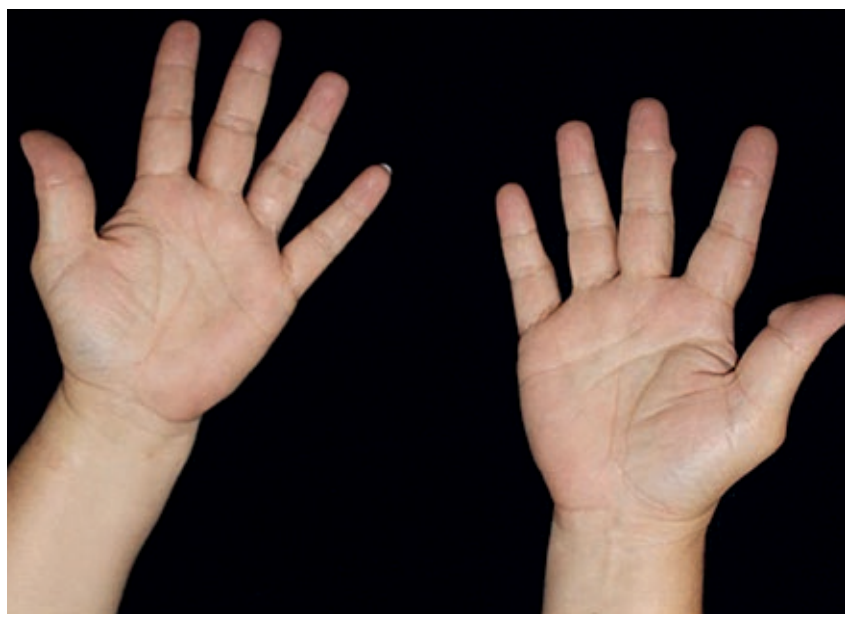

Figura 1 - Visão panorâmica de nódulos subcutâneos em quirodáctilos.

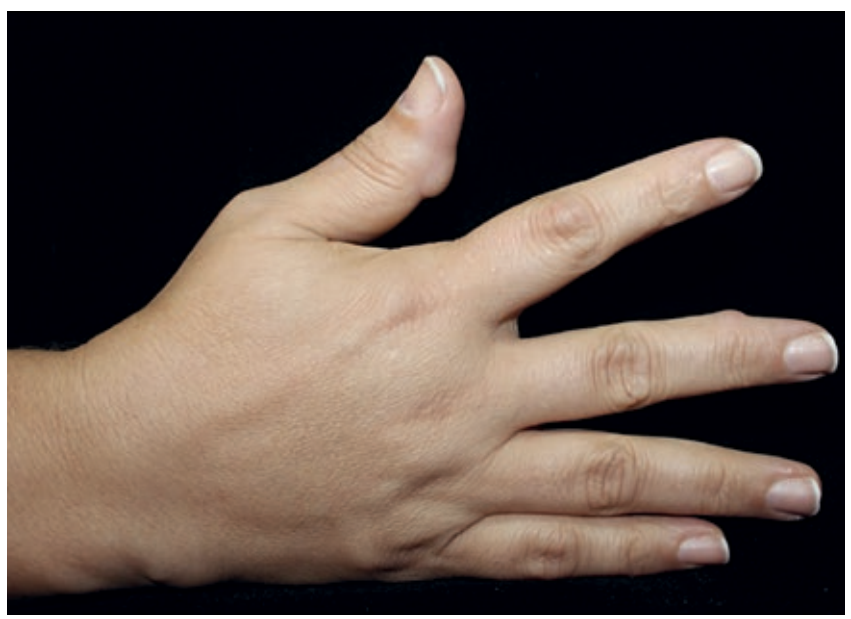

Figura 2 - Nódulos subcutâneos em bordas laterais dos quirodáctilos.

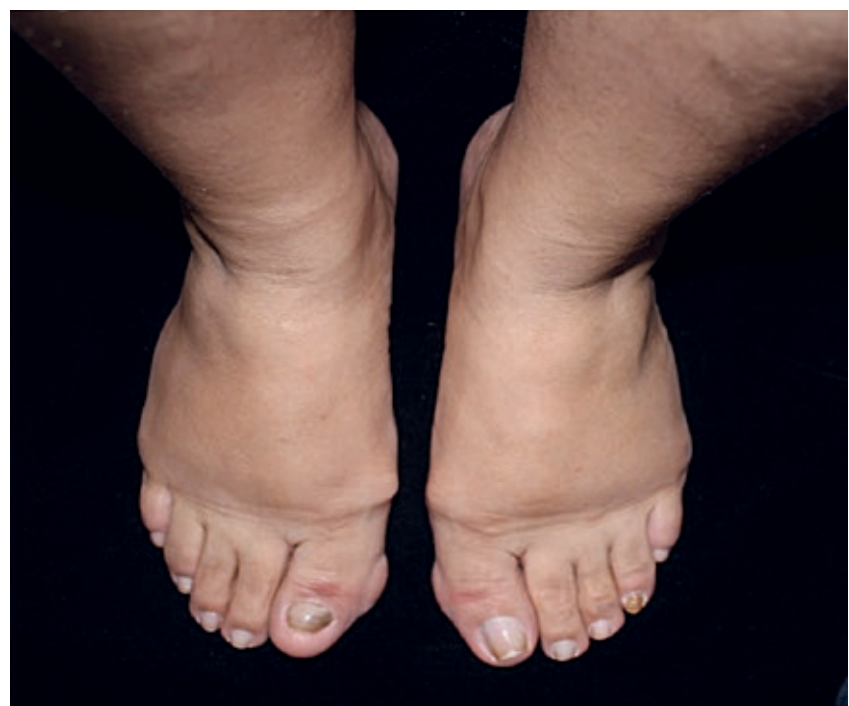

Figura 3 - Nodulações subcutâneas em hálux bilateralmente.

desde fevereiro de 2014, portanto 1 ano e 7 meses antes da consulta no serviço de Dermatologia, com início na borda lateral da terceira interfalangeana distal (IFD) direita de caráter não doloroso à palpação e sem sinais flogísticos aparentes. A dose acumulada de metotrexato na época do surgimento dos nódulos era 1860mg. Ao longo de um ano estes nódulos evoluíram para primeira e terceira interfalangeanas proximais (IFP) esquerda, além de porção medial dos hálux direito e esquerdo (Figs. 1, 2 e 3).

Estas lesões de consistência fibroelástica e recobertas por pele normal são aderentes aos planos superficiais e com diâmetro maior em torno de $3 \mathrm{~cm}$. As hipóteses diagnósticas iniciais foram calcinose cutânea iatrogênica e nódulos reumatóides.

Após a realização de radiografia das mãos (Fig. 4), não foi verificada calcificação em topografia de nódulos subcutâneos,

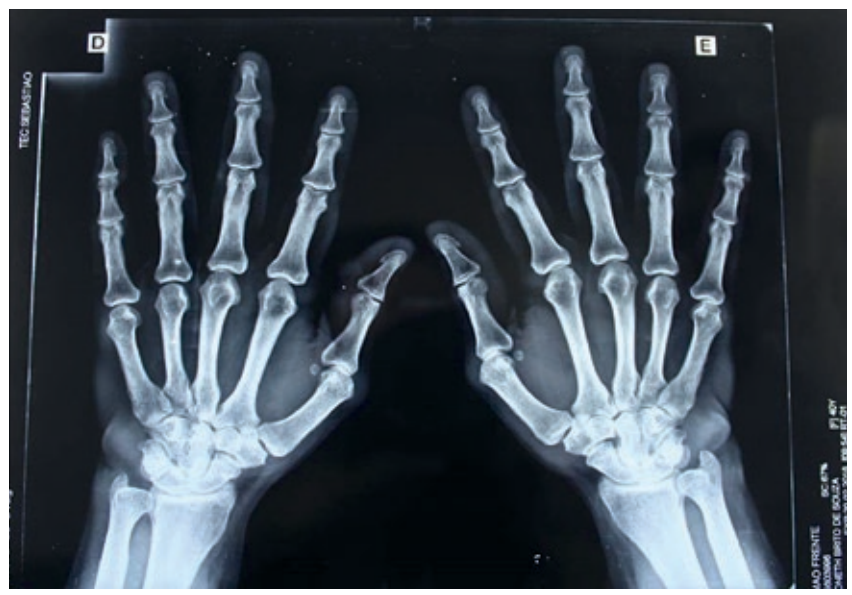

Figura 4 - Radiografia das mãos sem evidências de calcinose em topografia de nódulos. 


\section{Caso Clínico}

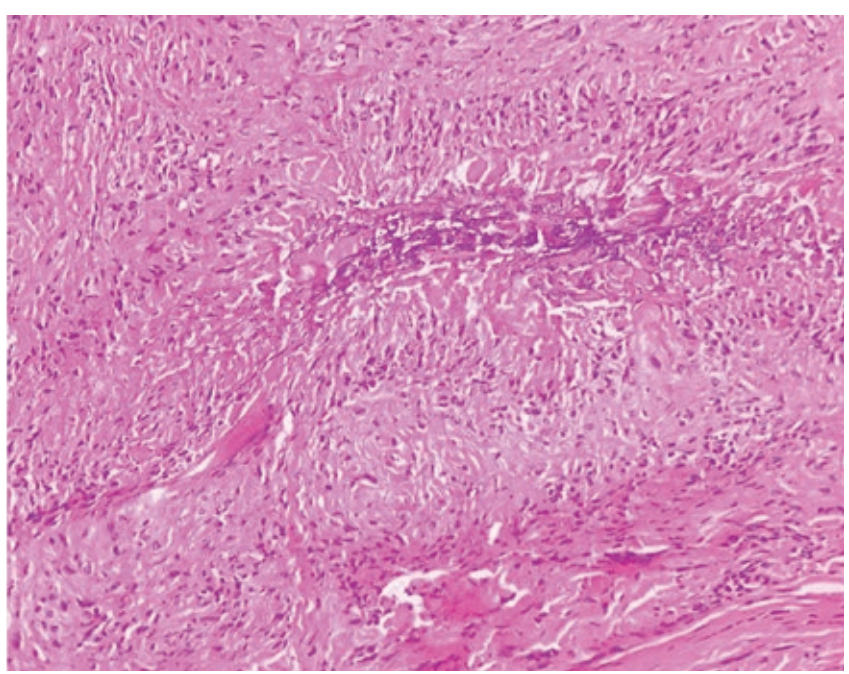

Figura 5 - Exame histopatológico evidenciando células epitelioides com periferia em paliçada e degeneração do colágeno central com aspecto basofílico.

sendo a calcinose cutânea idiopática descartada. A paciente foi submetida à biópsia de pele para confirmação diagnóstica, cujo estudo histopatológico revelou granuloma formado por histiócitos, células epitelioides com periferia em paliçada e degeneração do colágeno central com aspecto basofílico e, entre a camada de células em paliçada, existe material hialino e a degeneração do colágeno central, compatível com nódulos reumatoides (Fig. 5).

\section{DISCUSSÃO}

A nodulose acelerada foi observada pela primeira vez em 1986 por Kremer e Lee durante um estudo da terapia de MTX para AR. Foi descrita inicialmente como um efeito exclusivo de pacientes com AR que faziam uso do MTX, sendo considerada apenas uma exacerbação da própria doença. ${ }^{6}$ Posteriormente, observou-se a ocorrência da NA em outras doenças não nodulares como artrite psoriática, doença mista do tecido conjuntivo, dermatomiosite e AR soronegativa.

A NA acomete entre $2 \%$ a $11 \%$ dos doentes adultos com AR em uso do MTX, com maior prevalência no sexo masculino. ${ }^{5} \mathrm{O}$ desenvolvimento da NA não é uma exclusividade do uso do MTX. Existem relatos de NA com infliximab ${ }^{3}$ e etanercept, assim como agravamento dos nódulos quando o MTX está associado. Relatos têm mostrado que o tempo entre o início do tratamento com MTX e a ocorrência de nodulose varia de 3 meses a 12 anos, e a dose cumulativa de metotrexato varia entre 90 a $7200 \mathrm{mg}^{7}$ Com características diferentes dos nódulos subcutâneos da $A R$, a nodulose por MTX é de aparecimento rápido, pode ser umbilicada, possui conformação menor ( $0,5 \mathrm{~m}$ de diâmetro) e apresenta maior quantidade de nódulos. Acomete preferencialmente falanges, porém também é descrita em tendão de Aquiles, planta e lateral dos pés e porção distal do antebraço. ${ }^{1,8}$

No caso que relatamos foi utilizada a Escala de Probabilidade de uma Reação Adversa a Medicamento, de Naranjo, cujo score 6 foi atribuído, implicando em provável causa de nodulose induzida por uso de MTX. ${ }^{7}$

Na histologia da NA é possível observar a presença de células multinucleadas em paliçada, zonas concêntricas, com necrose fibrinoide na região interna, assemelhando-se com a histologia típica dos nódulos reumatoides. ${ }^{1,5,9}$ o que se visualizou no presente caso (Fig. 5). A coloração imuno-histoquímica pode mostrar histiócitos positivos para CD68 e lisozima. Há relato de caso com expressão de metaloproteinases de matriz (MMP) MMP-2, MP-3, MMP-9 e Ki67 na pele, sugerindo presença de processo inflamatório granulomatoso ativo na NA, porém sem expressão das três últimas proteínas no tecido sinovial do mesmo paciente. ${ }^{10}$

Evidências sugerem que o MTX estimula a formação de granulomas mediante a ativação de recetores macrofágicos de adenosina $\mathrm{A} 1$ já que um estudo imuno-histoquímico mostrou uma forte expressão de células CD4+ e marcadores macrofágicos. Existem dois tipos de recetores macrofágicos que se ligam à adenosina, o recetor $\mathrm{A} \mathrm{l}$, que responde às baixas doses de adenosina e tem efeito pró-inflamatório e o receptor A2 que necessita de doses mais elevadas de adenosina e tem efeito anti-inflamatório. $O$ efeito anti-inflamatório do MTX ocorre parcialmente devido ao facto de este fármaco aumentar a concentração de adenosina extracelular. $O$ estímulo do recetor Al favorece a polarização celular, formação de sincício e de células gigantes. Diferenças nos níveis tissulares de MTX e, consequentemente, dos níveis de adenosina podem levar ao efeito colateral pró-inflamatório $A 1$ com indução de $N A$, apesar do controle do quadro inflamatório de AR via receptores de adenosina A2 (Fig. 6).'

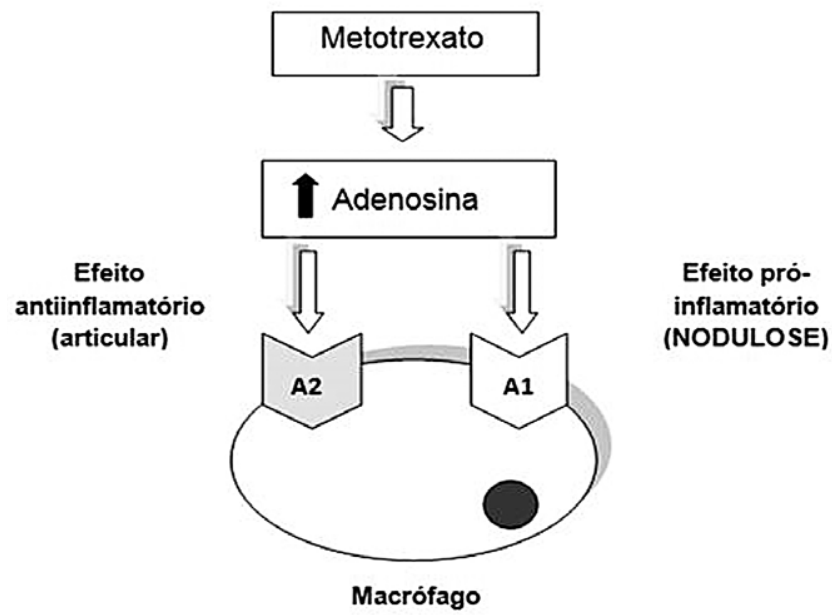

Figura 6 - Doses baixas de adenosina estimulam o recetor A- 1 do macrófago (efeito pró-inflamatório) causando à formação de nódulos. Já doses elevadas estimulam o receptor A-2 com efeito antiinflamatório.

Existem poucas opções de tratamento da NA. Na vigência dos medicamentos para AR associados à NA, os nódulos podem apresentar remissão espontânea ou melhoria quando associada colchicina, hidroxicloroquina, sulfasalazina ou 


\section{Caso Clínico}

d-penicilamina. ${ }^{6,7,11}$ Apenas a suspensão dos fármacos causadores podem facilitar a remissão dos nódulos, mas estes podem reaparecer com reutilização de MTX.6,12 A excisão cirúrgica e a infiltração com corticoide são descritas como alternativas terapêuticas. 'Muita controvérsia existe sobre a suspensão de MTX, principalmente nos casos em que a artrite responde bem a esse tratamento. No entanto, a possibilidade de nodulose em órgãos internos, com repercussões graves, é motivo de preocupação ao se optar pela continuidade deste tratamento.

Conflitos de interesse: Os autores declaram não possuir conflitos de interesse. Suporte financeiro: $O$ presente trabaIho não foi suportado por nenhum subsídio ou bolsa. Confidencialidade dos dados: Os autores declaram ter seguido os protocolos do seu centro de trabalho acerca da publicação dos dados de doentes. Protecção de pessoas e animais: Os autores declaram que os procedimentos seguidos estavam de acordo com os regulamentos estabelecidos pelos responsáveis da Comissão de Investigação Clínica e Ética e de acordo com a Declaração de Helsínquia da Associação Médica Mundial.

Conflicts of interest: The authors have no conflicts of interest to declare. Financing Support: This work has not received any contribution, grant or scholarship. Confidentiality of data: The authors declare that they have followed the protocols of their work center on the publication of data from patients. Protection of human and animal subjects: The authors declare that the procedures followed were in accordance with the regulations of the relevant clinical research ethics committee and with those of the Code of Ethics of the World Medical Association (Declaration of Helsinki).

\section{REFERÊNCIAS}

1. Guidolin F, Esmanhotto L, Magro C E, Silva M B, Skare T. Nodulose por metotrexato. Rev Bras Reumatol. 2005; 45:259-61.

2. Brasil. Ministério da Saúde. Rede Brasileira de Avaliação
Tecnologia e Saúde. Medicamentos biológicos para o tratamento da artrite reumatoidereumatoide. Brasil: MS;2012.

3. Diniz MS, Almeida LMC, Machado PJ, Alves MFF, Alvares MCB. Nódulos reumatoides: avaliação comparativa da resposta terapêutica com triancinolona e fluoruracil intralesional. An Bras Dermatol. 2011 ; 86:1236-8.

4. Rosa DJ de F, Paula EA, Bonfante HL, Bonfante $H$ de $L$, Areal CE de C, Baião GS, et al. Nodulose acelerada na artrite reumatoide durante terapia com Leflunomida. Rev Bras Reumatol. 2007; 47:228.

5. Román C, Palop MJ, Morán AG, Asensio MP, Ramos ML, Martín R. Nodulosis acelerada por metotrexato en un paciente con artritis reumatoide y síndrome de Sjögren. Actas Dermosifiliogr. 2003; 94:470-4.

6. Sayah A, Joseph C. Rheumatoid arthritis: A review of the cutaneous manifestations. J Am Acad Dermatol. 2005; 53:191-209.

7. Takashima S, Ota M. Methotrexate-induced nodulosis. Clinical Images - Can Med Assoc J. 2015; 187:E327.

8. Costa J de O, Lemos LL, Machado MA, Almeida AM, Kakehasi AM, Araújo VE, et al . Infliximabe, metotrexato e sua combinação no tratamento da artrite reumatoide: revisão sistemática e metanálise. Rev Bras Reumatol. 2015; 55:146-58.

9. Guidelli GM, Garcia-Gonzalez E, Selvi E. Benign rheumatoid nodulosis. Société francaise de Rhumatologie. Paris: Elsevier Masson; 2015.

10. Matsushita I, Uzuki M, Matsumo H, Sugiyama E, Kimura T. Rheumatoid nodulosis during methotrexate therapy in a patient with rheumatoid arthritis. Mod Rheumatol. 2006; 16:401-3.

11. Akiyama N. Toyoshima $M$, Kono $M$, Nakamura $Y$, Funai K, Suda T. Methotrexate-induced accelerated pulmonary nodulosis. Am J Respir Crit Care Med. 2015; 192:252-3.

12. Tilstra J, Lienesch D. Rheumatoid nodules. Dermatol Clin. 2015; 33:361-71. 